\title{
Expression patterns of angiogenic and lymphangiogenic factors in ductal breast carcinoma in situ
}

\author{
P Wülfing ${ }^{*, 1,6}$, C Kersting ${ }^{2,6}$, H Buerger ${ }^{2}$, B Mattsson', R Mesters ${ }^{3}$, C Gustmann ${ }^{4}$, B Hinrichs ${ }^{5}$, J Tio', W Böcker ${ }^{2}$ \\ and L Kiesel'
}

'Department of Obstetrics and Gynecology, University of Münster, Albert-Schweitzer-Str. 33, 48I 29 Münster, Germany; ${ }^{2}$ Gerhard-Domagk-Institute of Pathology, University of Münster, Albert-Schweitzer-Str. 33, 48129 Münster, Germany; ${ }^{3}$ Department of Hematology and Oncology, University of Münster, Albert-Schweitzer-Str. 33, 48129 Münster, Germany; ${ }^{4}$ Institut für Pathologie, St Vincenz-Krankenhaus Limburg, Germany; ${ }^{5}$ nstitut für Pathologie, KölnRodenkirchen, Germany

The objective of this study was to investigate expression of various growth factors associated with angiogenesis and lymphangiogenesis and of their receptors in ductal carcinomas in situ of the breast (DCIS). We studied protein expression of basic fibroblast growth factor (bFGF), vascular endothelial growth factor (VEGF)-A, endothelin (ET)-I, and VEGF-C, and their receptors bFGF-RI, Flt-I, KDR, ET ${ }_{A} R, E_{B} R$, and Flt-4 immunohistochemically in 200 DCIS (pure DCIS: $n=96$; DCIS adjacent to an invasive component: $n=104$ ) using self-constructed tissue microarrays. Basic fibroblast growth factor-RI, VEGF-C, Flt-4, and ET $R$ were expressed in the tumour cells in the majority of cases, whereas bFGF and Flt-I expression was rarely observed. VEGF-A, KDR, $E T-I$, and $E T_{B} R$ were variably expressed. The findings of VEGF-C and its receptor Flt-4 as lymphangiogenic factors being expressed in tumour cells of nearly all DCIS lesions and the observed expression of various angiogenic growth factors in most DCIS suggest that in situ carcinomas are capable of inducing angiogenesis and lymphangiogenesis. Moreover, we found a higher angiogenic activity in pure DCIS as compared to DCIS with concomitant invasive carcinoma. This association of angiogenic factors with pure DCIS was considerably more pronounced in the subgroup of non-high-grade DCIS $(n=103)$ as compared with high-grade DCIS ( $n=94)$. Determination of these angiogenic markers may therefore facilitate discrimination between biologically different subgroups of DCIS and could help to identify a particularly angiogenic subset with a potentially higher probability of recurrence or of progression to invasiveness. For these DCIS, targeting angiogenesis may represent a feasible therapeutic approach for prevention of progression of DCIS to invasion.

British Journal of Cancer (2005) 92, I720- 1728. doi:I0.1038/sj.bjc.6602567 www.bjcancer.com

Published online 19 April 2005

(c) 2005 Cancer Research UK

Keywords: angiogenesis; lymphangiogenesis; immunohistochemistry; breast cancer; ductal carcinoma in situ; growth factors; receptors

Angiogenesis is known to be a prerequisite for tumour growth beyond a few $\mathrm{mm}^{3}$ in size (Folkman, 1995). Several studies have shown that the angiogenic potential as assessed by tumour microvessel density (MVD) of breast carcinomas correlates with tumour progression and metastasis, thus predicting a poor clinical outcome in breast cancer patients (Gasparini et al, 1994; Heimann et al, 1996). Also, lymphangiogenesis in breast cancer is supposed to contribute to tumour progression and poor survival by predisposing to metastatic spread via the lymphatic system (Nakamura et al, 2003).

The family of vascular endothelial growth factor (VEGF) proteins is a group of angiogenic factors that regulate the growth of endothelial cells. There are four major VEGF isoforms, VEGF-A, VEGF-B, VEGF-C, and VEGF-D. Three main tyrosine-kinase receptors (RTKs) have been identified: VEGFR-1 (also known as Flt-1) (de Vries et al, 1992), VEGFR-2 (also known as Flk-1 in mouse or KDR in human) (Millauer et al, 1993), and VEGFR-3 (also known as Flt-4) (Pajusola et al, 1994).

*Correspondence: Dr P Wülfing; E-mail: wuelfip@uni-muenster.de

${ }^{6}$ Shared first authorship

Received 10 November 2004; accepted 10 March 2005; published online 19 April 2005
Vascular endothelial growth factor-A is considered to be the most crucial regulator of angiogenesis and vasculogenesis (Ferrara et al, 2003) and its expression has been demonstrated in cancer cells of various human tumours including breast cancer (Yoshiji et al, 1996; De Jong et al, 1998a). In breast carcinomas, VEGF-A expression correlates with angiogenesis and seems to represent a useful prognostic marker for poor outcome (Obermaier et al, 1997; Gasparini, 2001). The biological effects of VEGF-A are mediated by Flt-1 and KDR binding VEGF-A with high affinity (Mustonen and Alitalo 1995). Although Flt-1 was the first receptor to be identified as a VEGF receptor (de Vries et al, 1992), there is much evidence that Flt-1 performs an inhibitory role in mitogenesis of endothelial cells by sequestering VEGF-A and preventing its interaction with $\mathrm{KDR}$, whereas KDR is considered to be the major mediator of angiogenesis (Ferrara et al, 2003). Initially, expression of Flt-1 and KDR was believed to be restricted to the vascular endothelium, but to date these receptors have also been detected in several types of nonendothelial cells including breast cancer cells, suggesting an autocrine effect of VEGF-A on tumour cells (De Jong et al, 1998a; Kranz et al, 1999). The clinical significance of VEGF-A receptor expression in breast cancer is yet unclear. On the one hand, it has been reported that Flt-1 overexpression improves survival in breast cancer, whereas KDR expression is associated with a poor 
prognosis (Zhukova et al, 2003). However, another study has demonstrated, Flt-1 to be related to a higher metastatic and local recurrence risk in breast cancer patients (Dales et al, 2004).

Flt-4 is an RTK that is similar to the two VEGF-A receptors in structure but primarily represents a marker for lymphatic endothelial cells and which is also expressed in epithelial cells of various malignant tissues. Although VEGF-C appears to be the primary lymphangiogenic factor, it also links angiogenesis with lymphangiogenesis, as it can stimulate both processes by activating Flt-4 (Jeltsch et al, 1997) and KDR (Cao et al, 1998), respectively. Moreover, an autocrine growth stimulation pattern of VEGF-C via Flt-4 has been suggested in tumours (Van Trappen et al, 2003). In breast cancer, expression of VEGF-C and Flt-4 is associated with angiogenesis and lymphangiogenesis (Valtola et al, 1999; Kinoshita et al, 2001). Also, a clinicopathological significance of VEGF-C and Flt-4 in breast cancer has been described, since their expression correlated with lymph node metastasis and decreased survival of patients (Kinoshita et al, 2001; Nakamura et al, 2003).

Another category of angiogenic activators evaluated in human breast carcinomas is the fibroblast growth factor (FGF) family. FGFs are important signalling molecules contributing to angiogenesis, tumour growth, and tumour progression (Mason, 1994; Kern and Lippman, 1996). Among FGFs, basic FGF (bFGF) which binds to specific RTKs, FGFRs (Mohammadi et al, 1997), is the most active growth factor for endothelium and several studies have demonstrated its expression in breast cancer (Luqmani et al, 1992; Colomer et al, 1997; Smith et al, 1999). However, the clinical relevance of bFGF expression in breast cancer is yet unclear, since conflicting results have been reported (Colomer et al, 1997; Smith et al, 1999).

Recently, the endothelin (ET)-axis comprising the vasoactive peptide ET-1 and the cell-surface receptors, $\mathrm{ET}_{\mathrm{A}} \mathrm{R}$ and $\mathrm{ET}_{\mathrm{B}} \mathrm{R}$, came into focus due to its emerging role in cancer (Nelson et al, 2003). Increased ET-1 expression has been demonstrated in various human malignancies as well as in breast cancer. It appears that the effects of the ET-axis on tumorigenesis and tumour progression are mediated by several mechanisms including proliferation, angiogenesis, and inhibition of apoptosis (Nelson et al, 2003). Endothelin-1 contributes to the process of angiogenesis, stimulating endothelial cell growth predominantly through $\mathrm{ET}_{\mathrm{B}} \mathrm{R}$ and inducing vascular smooth muscle cell and pericyte mitogenesis mediated through $\mathrm{ET}_{\mathrm{A}} \mathrm{R}$ (Bek and McMillen, 2000; Salani et al, 2000). Previously, we have demonstrated an increased expression of the ET-axis in breast carcinomas. Expression of $\mathrm{ET}_{\mathrm{A}} \mathrm{R}$ correlated with aggressive types of breast cancer and poor clinical outcome, indicating a potential connection between the ET-axis and disease progression in breast cancer (Wülfing et al, 2003a). Similar to findings in ovarian cancer (Salani et al, 2000), we observed a significant correlation between expression of the ET axis and neovascularisation and VEGF expression of breast carcinomas (Wülfing et al, 2004b). Further studies have suggested that activation of $\mathrm{ET}_{\mathrm{A}} \mathrm{R}$ by ET-1 induces the production of VEGF, which in turn stimulates tumour growth and angiogenesis by increasing the levels of hypoxia-inducible factor-1 (HIF-1 $\alpha$ ), in a time- and dose-dependent manner (Spinella et al, 2002).

The switch of a tumour to an angiogenic phenotype is considered to be critical for progression and metastasis (Folkman et al, 1989). In DCIS, two distinct vascular patterns have been described: (1) an increased stromal vascular density which is thought to result from angiogenic factors being released by accessory cells; (2) an increase in periductal vessels as an effect of angiogenic factors secreted by intraductal tumour cells (Guidi et al, 1994; Engels et al, 1997).

This last pattern has been shown to correlate with the development of an invasive recurrence (Teo et al, 2003). Thus, it is conceivable that an increase in periductal angiogenesis may contribute to the transformation from DCIS to invasive carcinoma.
In the present study, we therefore analysed expression of several surrogate markers of angiogenesis and lymphangiogenesis in DCIS using a tissue microarray (TMA) with 902 cores from 200 DCIS specimens. The objective was to see whether these markers are associated with established histopathological characteristics and to assess whether there are different expression patterns between the groups of DCIS with $(n=104)$ and without $(n=96)$ coexistent invasive carcinoma.

\section{MATERIALS AND METHODS}

\section{Patients and tumours}

A total of 200 patients with DCIS were included in the study. Among these, 96 patients had a pure DCIS and in 104 patients the DCIS was associated with an invasive breast carcinoma (coexistent DCIS). All cases were classified according to the criteria outlined by Holland et al (1994) considering the nuclear grading and architectural features. Based on this classification, cases were graduated as low grade $(n=54)$, intermediate grade $(n=49)$, and high grade $(n=94)$. With respect to these criteria, cases were divided into 'non-high-grade' (low grade + intermediate grade) or 'high-grade' DCIS. The median age of patients was 59 years (range 18-94 years).

\section{Breast cancer TMA}

Routinely fixed paraffin-embedded tissue blocks containing DCIS were extracted from the files of pathology laboratories serving as donor blocks for the TMA. Sections were cut from each donor block and stained with haematoxylin and eosin. Using these slides morphologically representative regions were chosen from each of the 200 tumour samples and circled. At least four cylindrical $0.6 \mathrm{~mm}$ cores were acquired from the circled areas of each DCIS sample and precisely arrayed into a new recipient paraffin block $(20 \times 35 \mathrm{~mm})$ using a manual tissue arrayer (Beecher Instruments, Silver Spring, MD, USA). The final tissue set consisted of four blocks each containing 116-306 tumour sample cores for a total of 902 cores (Figure 1). The presence of DCIS in the arrayed samples was verified on haematoxylin-eosin-stained sections.

\section{Immunohistochemistry}

Table 1 presents all antibodies, dilutions, incubation times, and antigen-retrieval methods used. Tissue microarray blocks were cut with a microtome into $4 \mu \mathrm{m}$ sections that were mounted on poly-Llysine-coated glass slides and processed for immunohistochemistry. After deparaffinisation and rehydration, unspecific binding was blocked. Then, antigen retrieval by different pretreatment methods was followed by incubation with the primary antibody. After detection, sections were counterstained with haematoxylin. Appropriate negative (the first antibody was either omitted or replaced by non-immune rabbit IgG diluted to the same concentration as the first antibody) and positive (as shown in Table 1) controls were used throughout. Additionally, DCIS-TMA sections were stained for ER, PR and Her-2/neu by standard immunohistochemical methods as described previously (Wülfing et al, 2003b).

\section{Quantification}

Semiquantitative analysis of staining results from 902 tissue array cores was performed by two investigators in a blind-trial fashion without knowing the histopathological data for the corresponding case. Depending on the staining procedure varying numbers of tissue cores were detached, others did not contain a sufficient number of tumour cells. Also, if precise diagnosis of DCIS on the 

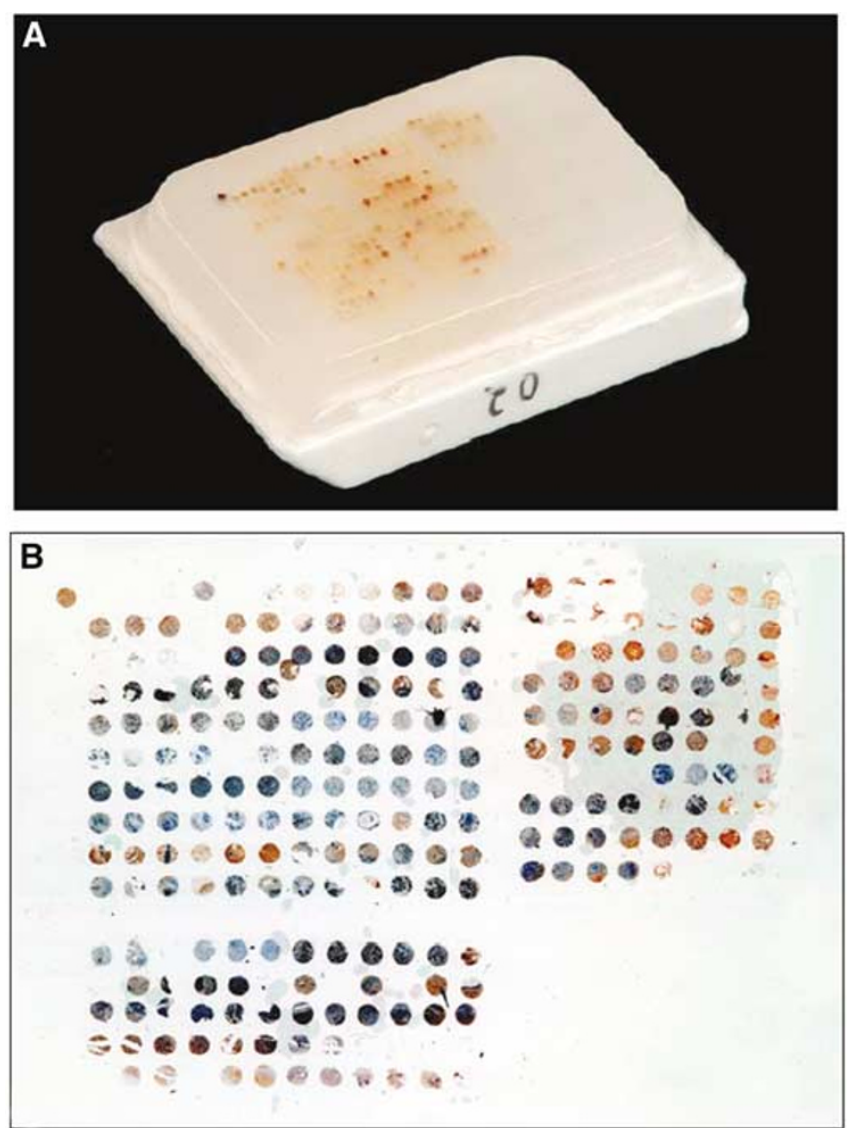

Figure I Tissue microarray. (A) Picture of a TMA; (B) stained section of a TMA.

TMA section was not possible, the case was disregarded. Therefore, some cases could not be analysed.

For evaluation of bFGF-R1, ET-1, $\mathrm{ET}_{\mathrm{A}} \mathrm{R}$, and $\mathrm{ET}_{\mathrm{B}} \mathrm{R}$ expression, intensity of the cytoplasmic immunostaining was scored semiquantitatively on a four-tiered scale (negative $=0$, weak $=1+$, moderate $=2+$, strong $=3+)$. We defined samples with a moderate $(2+)$ or strong $(3+)$ cytoplasmic immunostaining intensity to have an elevated expression of this marker and thus to be 'positive', respectively (Wülfing et al, 2004b). A similar score was used for VEGF-C and Flt-4, both showing a cytoplasmic and nuclear immunostaining, and for KDR expression, which was primarily observed in the cytoplasm but additionally showed a staining of the cell membranes. For Flt-1, the cytoplasmic immunostaining intensity was classified from 0 (negative) to $2+$ (moderate). Cases scored as $\geqslant 1+$ were considered to be Flt-1 positive. Expression of bFGF and VEGF-A was characterised as a negative or positive reaction according to both the intensity of the immunostaining and the percentage of stained tumour cells. Samples were judged to be positive if $\geqslant 10 \%$ of the tumour cells showed moderate or strong cytoplasmic immunoreaction (De Jong et al, 1998a). Her-2/neu staining was scored 0 (absent) to $3+$ (maximum cytomembranous staining), with a score $\geqslant 2+$ considered Her-2/neu-positive. ER and PR scores were calculated as the percentage of positively stained nuclei. ER and PR status were defined positive when $\geqslant 10 \%$ nuclei stained positively.

\section{Data analysis}

Staining results for the angiogenic and lymphangiogenic markers were correlated with results for ER, PR, and Her-2/neu, as well as with the nuclear grading of DCIS. According to the clinical practice, low-grade and intermediate-grade cases were taken together as 'non-high-grade' as opposed to the poorly differentiated 'high-grade' DCIS. Correlations were tested for statistical significance by cross-tables, applying Pearson's $\chi^{2}$ test and Fishers' exact test (SPSS 10.0). Differences between the groups of DCIS with $v s$ DCIS without an invasive carcinoma, as well as correlations between coexistent DCIS and the respective invasive component were also tested using $\chi^{2}$ test.

\section{RESULTS}

\section{Immunohistochemistry of the DCIS specimens}

Detailed staining results are depicted in Table 2. In the majority of cases, tumour cells of DCIS showed expression of Flt-4, bFGF-R1, VEGF-C, and $\mathrm{ET}_{\mathrm{A}} \mathrm{R}$, whereas Flt-1 and bFGF expression was rarely observed. A positive immunoreaction for KDR, ET-1, VEGF-A, and $\mathrm{ET}_{\mathrm{B}} \mathrm{R}$ in the tumour cells was present in a varying number of samples. The following immunohistochemical staining patterns of DCIS were observed:

\section{Vascular endothelial growth factor-A and VEGF-receptors 1 (Flt-1) and 2 (KDR)}

Vascular endothelial growth factor-A: A positive immunoreaction for VEGF-A was observed in about half of the DCIS samples. Most cases presented with a faint or moderate cytoplasmic staining of tumour cells (Figure 2C). Normal glandular cells were negative for VEGF-A, while myoepithelial cells stained positively. The stromal and connective tissue was mostly negative for VEGF-A.

Flt-1: Expression of Flt-1 in the tumour cells was found in very few cases of DCIS (16.1\%). Flt-1-positive cells showed a finely granular staining of the cytoplasm (Figure 2D). The peritumoral stroma often stained positively in Flt-1 positive cases. Normal glandular cells were Flt-1-negative.

KDR: About half of the DCIS cases (53.5\%) were considered to be KDR-positive. KDR features a strong cytoplasmic staining (Figure 2E). Normal glandular cells usually stained positively, while stroma and connective tissue remained negative.

\section{Vascular endothelial growth factor-C and VEGF-receptor 3 (Flt-4)}

Vascular endothelial growth factor-C: In all, $88 \%$ of DCIS showed intense staining and were considered to be VEGF-C-positive. Expression of VEGF-C protein was observed in the cytoplasm of tumour cells (Figure 2F). Little or no staining for VEGF-C was observed in normal breast epithelium. Stromal and connective tissues were VEGF-C negative.

Flt-4: For Flt-4, a strong staining of tumour cells was observed in most cases (95.4\%) (Figure 2G). Also, normal glandular cells were often positive, while stromal and connective tissues were Flt-4negative.

\section{Basic fibroblast growth factor and bFGF receptor}

Basic fibroblast growth factor: Positive nuclear staining of tumour cells with bFGF was present in only a few cases (12.3\%). In a small proportion of these positive cases, also a faint cytoplasmic staining was observed (Figure 2A). Normal glandular cells often showed immunoreaction for bFGF, while the stroma generally was bFGFnegative.

Basic fibroblast growth factor-R1: Almost all DCIS (94.4\%) showed a strong and homogenous cytoplasmic expression of bFGF-R1 in the tumour cells (Figure 2B); in few cases, also a nuclear staining was observed. In bFGF-R1-positive cases, stromal cells often exhibited a faint staining, too, while normal glandular cells generally were moderately positive. 
Table I List of antibodies and staining procedures used

\begin{tabular}{|c|c|c|c|c|c|c|c|}
\hline & Species & Pretreatment & Dilution & Incubation times & Detection & Pab source & Positive control \\
\hline \multicolumn{8}{|l|}{ Growth factors } \\
\hline VEGF-A & Rabbit Poly & PK (10 min) & ।:15 & $\begin{array}{l}25 \text { min PAb, } \\
20 \text { min Link AP, } \\
20 \text { min Strept AP, } \\
\text { 2*8 min modified 'Neufuchsin' }\end{array}$ & LSAB/AP & Santa Cruz & Inflammatory tissue \\
\hline VEGF-C & Rabbit Poly & $\mathrm{S}(35 \mathrm{~min})$ & $1: 25$ & $\begin{array}{l}25 \text { min PAb, } \\
20 \text { min Link AP, } \\
20 \text { min Strept AP, } \\
\text { 2*8 min modified 'Neufuchsin' }\end{array}$ & LSAB/AP & Santa Cruz & Inflammatory tissue \\
\hline bFGF & Rabbit Poly & $\mathrm{MW} 2 \times 7 \mathrm{~min}(450 \mathrm{~W})$ & 1:2000 & $\begin{array}{l}30 \mathrm{~min} \text { Dako Blocking Solution, } \\
210 \mathrm{~min} \text { PAb at } 37^{\circ} \mathrm{C}, \\
30 \mathrm{~min} \text { Bridge-Ab at } 23^{\circ} \mathrm{C}, \\
30 \mathrm{~min} 2 \mathrm{P}^{\text {ndP }} \text { Bridge-Ab at } 23^{\circ} \mathrm{C}\end{array}$ & APAAP & Santa Cruz & Inflammatory tissue \\
\hline ET-I & Mouse MAb & $\mathrm{S}(35 \mathrm{~min})$ & 1:500 & $\begin{array}{l}25 \text { min PAb, } \\
20 \text { min Link AP, } \\
20 \text { min Strept AP, } \\
2 * 8 \text { min DAB }\end{array}$ & LSAB/HRP & Affinity BioReagents & Ovarian carcinoma \\
\hline \multicolumn{8}{|l|}{ Receptors } \\
\hline Flt-I (VEGFR-I) & Rabbit Poly & $\mathrm{MW} 2 \times 7 \mathrm{~min}(450 \mathrm{~W})$ & |:400 & $\begin{array}{l}30 \mathrm{~min} \text { Dako Blocking Solution, } \\
210 \mathrm{~min} \text { PAb at } 37^{\circ} \mathrm{C}, \\
30 \mathrm{~min} \text { Bridge-Ab at } 23^{\circ} \mathrm{C}, \\
30 \mathrm{~min} 2 \mathrm{P}^{\text {ndP }} \text { Bridge-Ab at } 23^{\circ} \mathrm{C}\end{array}$ & APAAP & Santa Cruz & Inflammatory tissue \\
\hline KDR (VEGFR-2) & Mouse MAb & $\mathrm{MW} 2 \times 7 \mathrm{~min}(450 \mathrm{~W})$ & |:400 & $\begin{array}{l}30 \mathrm{~min} \text { Dako Blocking Solution, } \\
210 \mathrm{~min} \text { PAb at } 37^{\circ} \mathrm{C} \text {, } \\
30 \mathrm{~min} \text { Bridge-Ab at } 23^{\circ} \mathrm{C}, \\
30 \mathrm{~min} 2 \mathrm{P}^{\text {ndP }} \text { Bridge-Ab at } 23^{\circ} \mathrm{C}\end{array}$ & APAAP & Santa Cruz & Inflammatory tissue \\
\hline Flt-4 (VEGFR-3) & Rabbit Poly & $\mathrm{S}(35 \mathrm{~min})$ & 1:400 & $\begin{array}{l}25 \text { min PAb, } \\
20 \text { min secondary Agent (Link AP), } \\
20 \text { min tertiary Agent (Strept AP), } \\
\text { 2*8 min modified 'Neufuchsin' }\end{array}$ & LSAB/AP & Santa Cruz & Inflammatory tissue \\
\hline bFGF-RI & Rabbit Poly & $\mathrm{MW} 2 \times 7 \mathrm{~min}(450 \mathrm{~W})$ & 1:400 & $\begin{array}{l}30 \mathrm{~min} \text { Dako Blocking Solution, } \\
210 \mathrm{~min} \text { PAb at } 37^{\circ} \mathrm{C}, \\
30 \mathrm{~min} \text { Bridge-Ab at } 23^{\circ} \mathrm{C} \\
30 \mathrm{~min} 2 \mathrm{P}^{\text {ndP }} \text { Bridge-Ab at } 23^{\circ} \mathrm{C}\end{array}$ & APAAP & Santa Cruz & Inflammatory tissue \\
\hline $\mathrm{ET}_{\mathrm{A}} \mathrm{R}$ & Sheep MAb & Reveal 5 min; $\mathrm{H}_{2} \mathrm{O} 5$ min; Aurion BSA (I:30) 30 min & ।:800 & $\begin{array}{l}25 \mathrm{~min} \text { PAb, } \\
60 \mathrm{~min} \text { RAS }(1: 25) \text { at } 23^{\circ} \mathrm{C} \text {, } \\
60 \mathrm{~min} \text { Envision Detection Kit at } 23^{\circ} \mathrm{C}\end{array}$ & LSAB/HRP & Alexis & Prostate carcinoma \\
\hline $\mathrm{ET}_{\mathrm{B}} \mathrm{R}$ & Sheep MAb & $\mathrm{S}(35 \mathrm{~min})$ & $1: 100$ & $\begin{array}{l}25 \text { min } P A b, \\
20 \text { min secondary Ab (Rabbit-Anti-Sheep), } \\
20 \text { min Link AP, } 20 \text { min Strept AP, } \\
2 * 8 \text { min DAB }\end{array}$ & LSAB/HRP & Alexis & Smooth muscle tissue \\
\hline
\end{tabular}

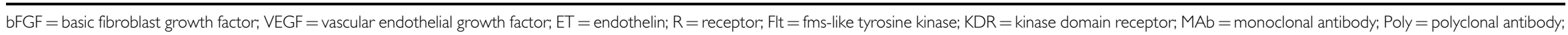

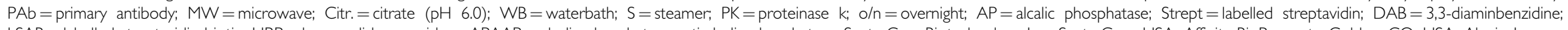

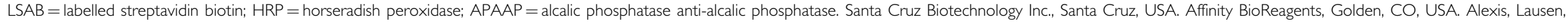
Switzerland. 
Table 2 Expression of growth factors and their receptors in tumour cells of DCIS ( $\mathrm{n}(\%)$ of evaluable cases with positive immunoreaction)

\begin{tabular}{|c|c|c|c|c|}
\hline Antigen & Total & Pure DCIS & Coexistent DCIS & $P^{\mathbf{a}}$ \\
\hline VEGF-A & $80 / 175$ (45.7\%) & $40 / 88$ (45.5\%) & $40 / 87(46 \%)$ & NS \\
\hline ET-I & $78 / 161$ (48.4\%) & $32 / 75(42.7 \%)$ & $46 / 86(53.5 \%)$ & NS \\
\hline \multicolumn{5}{|c|}{ Growth factor receptors } \\
\hline VEGFR-3 (Flt-4) & 165/173 (95.4\%) & $81 / 82$ (98.8\%) & $84 / 91$ (92.3\%) & $P=0.043$ \\
\hline bFGF-RI & $151 / 160$ (94.4\%) & $77 / 80$ (96.3\%) & $74 / 80$ (92.5\%) & NS \\
\hline$E T_{A} R$ & $126 / 165(76.4 \%)$ & $69 / 81(85.2 \%)$ & $57 / 84(67.9 \%)$ & $P=0.009$ \\
\hline $\mathrm{ET}_{\mathrm{B}} \mathrm{R}$ & $60 / 159$ (37.7\%) & $28 / 79(35.4 \%)$ & $32 / 80(40 \%)$ & NS \\
\hline
\end{tabular}

$\mathrm{NS}=$ nonsignificant. ${ }^{a} \chi^{2}$ test (pure DCIS versus coexistent DCIS).
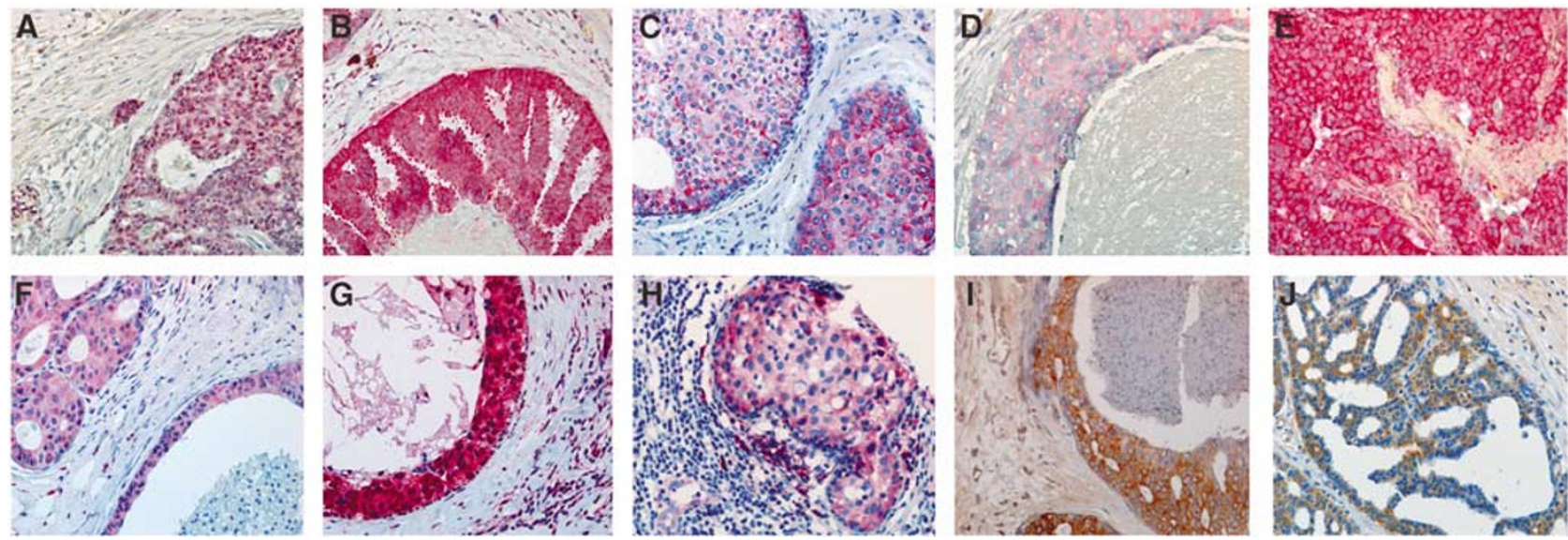

Figure 2 Ductal carcinoma in situ specimens with representative immunohistochemical staining patterns for (upper row) bFGF (A), bFGF-RI (B), VEGF$\mathrm{A}(\mathbf{C}), \mathrm{Flt}-\mathrm{I}(\mathbf{D}), \mathrm{KDR}(\mathbf{E})$, and (lower row) VEGF-C (F), Flt-4 (G), ET-I (H), ET ${ }_{\mathrm{A}} R(\mathbf{I}), \mathrm{ET}_{\mathrm{B}} \mathrm{R}(\mathbf{J})$.

\section{Endothelin-axis}

Positive cytoplasmic staining of tumour cells was observed for ET1 in $48.4 \%$, for $\mathrm{ET}_{\mathrm{A}} \mathrm{R}$ in $76.4 \%$, and for $\mathrm{ET}_{\mathrm{B}} \mathrm{R}$ in $37.7 \%$ of cases (Figure $2 \mathrm{H}-\mathrm{J}$ ). Normal glandular cells were mostly negative; in ET-positive cases, occasionally a weak staining of stromal components was present.

\section{Autocrine loops}

Expression patterns in DCIS were screened for cases in which the receptor and ligand are both expressed in the same cells, suggesting potential autocrine loops. Possible autocrine loops were observed for all receptor/ligand combinations in varying numbers of cases (Table 3). Coexpression of ligand and receptor in the tumour epithelium was most frequently found for the VEGF-C/ Flt- 4 combination ( $87 \%$ of cases), followed by the combinations of VEGF-C/KDR (51\%), ET-1/ET ${ }_{A}$ R (37\%), ET-1/ET ${ }_{B} \mathrm{R}(26 \%)$, and VEGF-A/KDR (25\%).

\section{Association of angiogenic markers with histopathological features}

The following associations between expression of angiogenic markers and other histopathological parameters were observed: $\mathrm{ET}_{\mathrm{A}} \mathrm{R}$ and $\mathrm{ET}_{\mathrm{B}} \mathrm{R}$ expression correlated with ER-negative DCIS
Table 3 Coexpression of ligand and respective receptor in the same DCIS specimen indicating potential autocrine loops

\begin{tabular}{lc}
\hline Ligand/Receptor & n/total (\%) \\
\hline VEGF-A/Flt-I & $13 / 166(7.8 \%)$ \\
VEGF-A/KDR & $36 / 147(24.5 \%)$ \\
VEGF-C/Flt-4 & $143 / 165(86.7 \%)$ \\
VEGF-C/KDR & $78 / 152(51.3 \%)$ \\
bFGF/bFGF-RI & $17 / 163(10.4 \%)$ \\
ET-I/ET $A R$ & $60 / 161(37.3 \%)$ \\
ET-I/ET $_{B} R$ & $42 / 161(26.1 \%)$ \\
\hline
\end{tabular}

( $P=0.017$ and $P<0.001$, respectively). In contrast, bFGF expression was associated with ER expression $(P=0.080)$, PR expression $(P=0.003)$, lack of Her-2/neu expression $(P=0.013)$, and with non-high-grade DCIS $(P=0.005)$. For Flt-1, a trend towards a negative correlation with Her-2/neu expression was observed $(P=0.097)$. No further associations between angiogenic markers and histopathological features examined were found. 
Different expression patterns in pure DCIS vs DCIS with a coexisting invasive carcinoma

Comparing the expression of angiogenic markers between the groups of DCIS with $(n=104)$ vs DCIS without $(n=96)$ coexisting invasive carcinoma revealed that expression of VEGF-C, KDR, Flt4 , and $\mathrm{ET}_{\mathrm{A}} \mathrm{R}$ was significantly more frequent in pure DCIS than in DCIS with an adjacent invasive carcinoma (Table 2). These differences between both DCIS groups were significantly more pronounced in the subgroup of non-high-grade DCIS as compared with high-grade DCIS (Table 4). In contrast, Flt-1 was significantly higher expressed in the group of DCIS with an adjacent invasive carcinoma irrespective of nuclear grading (Tables 2 and 4 ).

To evaluate whether these different expression patterns of angiogenic markers between pure and coexistent DCIS merely reflect an unequal distribution of DCIS with respect to histopathological and clinical features between both groups, possible associations with nuclear grading, ER-, PR-, and Her-2/neu-status and patients' age were analysed. As shown in Table 5, no significant differences were observed between both groups with respect to these parameters.

\section{Correlations between in situ and invasive carcinoma}

To assess whether expression of classic histopathological factors and angiogenic markers in coexistent DCIS is determined by expression patterns in the respective invasive carcinomas, staining results for the in situ and the invasive (IBC) components of each patient in the coexistent DCIS group were compared. Among the angiogenic factors, we focused on those which were differentially expressed in the groups of pure and coexistent DCIS. Analysis of $\mathrm{ET}_{\mathrm{A}} \mathrm{R}$ (ET $\mathrm{ET}_{\mathrm{A}} \mathrm{R}$-positive; DCIS: $67.9 \%$ vs IBC: $65.5 \%$ of cases), VEGF-
C (VEGF-C positive; DCIS: $80.4 \%$ vs IBC: $88.6 \%$ ), Flt-4 (Flt-4 positive; DCIS: $92.3 \%$ vs IBC: $93.3 \%)$, and Her-2/neu (Her-2/neu positive; DCIS: $21.9 \%$ vs IBC: $16.4 \%$ ) expression revealed a similar frequency of positive staining in the in situ and the invasive carcinomas. In contrast, expression of ER (ER-positive; DCIS: 26.9\% vs IBC: $61.5 \%$ of cases), PR (PR-positive; DCIS: $35.1 \%$ vs IBC: $48.1 \%$ ), Flt-1 (Flt-1 positive; DCIS: $28.1 \%$ vs IBC: $44.2 \%$ ), and

Table 5 Distribution of clinical and histopathological characteristics in the subgroups of pure vs coexistent DCIS

\begin{tabular}{lccc}
\hline Parameter & Pure DCIS & Coexistent DCIS & P \\
\hline Patients' age (years) & $60.5 \pm 13.6$ & $57.3 \pm 14.4$ & NS \\
$\begin{array}{l}\text { Estrogen receptor } \\
\quad \text { Negative }\end{array}$ & $46 / 70(65.7 \%)$ & $57 / 78(73.1 \%)$ & NS \\
$\quad$ Positive & $24 / 70(34.3 \%)$ & $21 / 78(26.9 \%)$ & \\
Progesterone receptor & & & \\
$\quad$ Negative & $41 / 69(59.4 \%)$ & $50 / 77(64.9 \%)$ & NS \\
$\quad$ Positive & $28 / 69(40.6 \%)$ & $27 / 77(35.1 \%)$ & \\
& & & \\
Her-2/neu & & $57 / 73(78.1 \%)$ & NS \\
$\quad$ Negative & $57 / 73(78.1 \%)$ & $16 / 73(21.9 \%)$ & \\
$\quad$ Positive & $16 / 73(21.9 \%)$ & & NS \\
Nuclear grade & & $46 / 101(45.5 \%)$ & \\
$\quad$ Non-high-grade & $57 / 96(59.4 \%)$ & $55 / 101(54.5 \%)$ & \\
High-grade & $39 / 96(40.6 \%)$ & & \\
\hline
\end{tabular}

NS = nonsignificant.

Table 4 Expression of growth factors and growth factor receptors stratified for nuclear grading

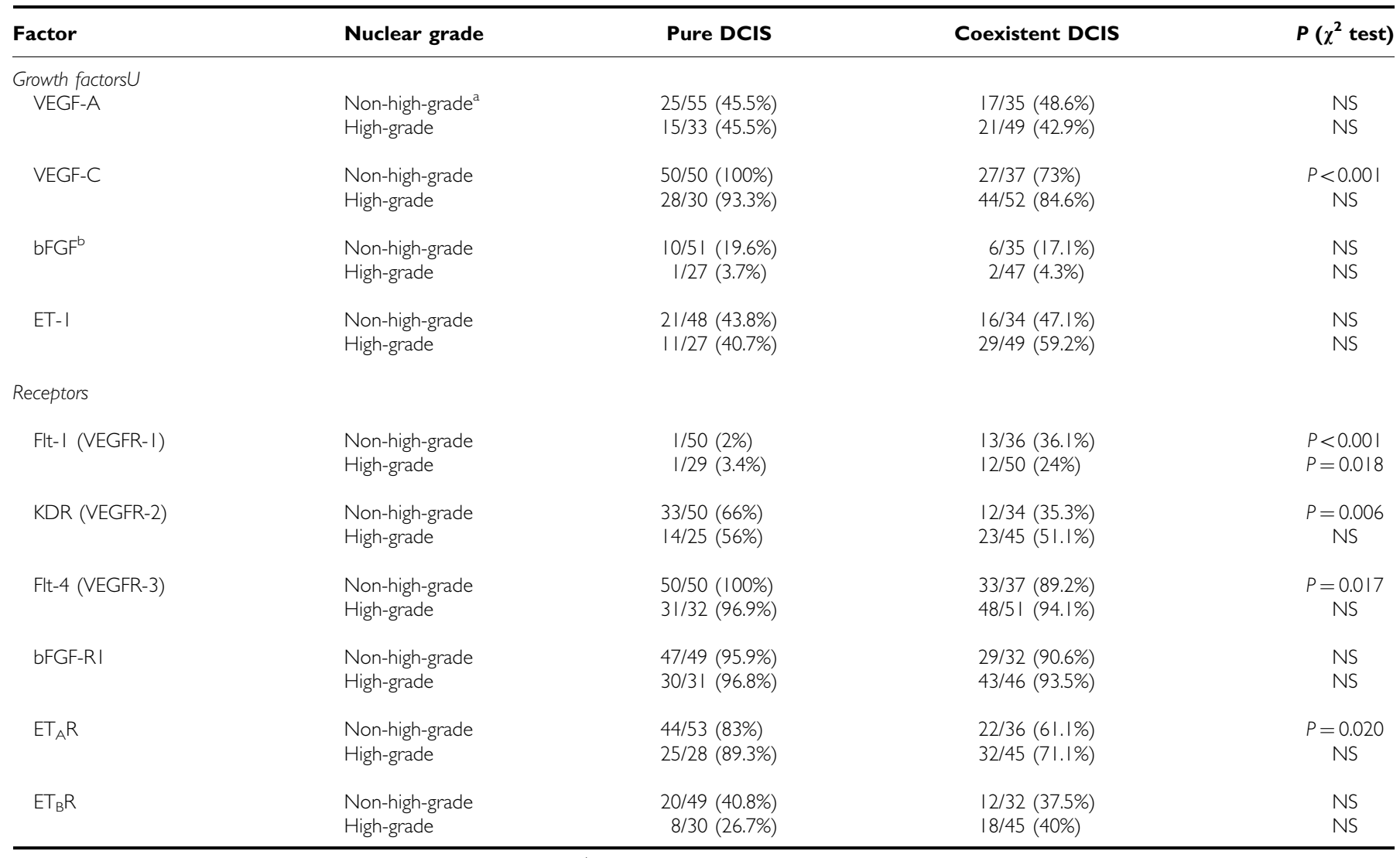

NS $=$ nonsignificant. ${ }^{a}$ Non-high-grade $=$ low + intermediate grade DCIS. ${ }^{b}$ Logistic regression showed a significant correlation between bFGF expression and grading $(P=0.009)$. 
KDR (KDR positive; DCIS: $45.1 \%$ vs IBC: $59.6 \%$ ) was significantly more frequent in the invasive component than in the coexistent in situ lesion (each $P<0.05$ ). Moreover, a close concordance was observed with respect to nuclear grading of the in situ and histological grading of the respective invasive component (Kruskal Wallis test; $P<0.001)$.

\section{DISCUSSION}

Tumour progression is characterised by the uncontrolled growth of tumour cells which may then invade the surrounding host tissue and metastasise to distant organs. The growth of small tumours is initially limited by the distance beyond which nutrients and oxygen can diffuse. Thus, angiogenesis is known to be a prerequisite for tumour growth beyond a few $(1-3) \mathrm{mm}^{3}$ in size. Following the 'angiogenic switch' of a tumour, rapid tumour growth, local invasion, and, ultimately, metastasis occur (Folkman et al, 1989). The identification of an increased vascular density around DCIS in a number of studies (Guidi et al, 1994; Engels et al, 1997; Teo et al, 2003) and the observed association of higher vascularity in DCIS with invasive recurrence (Teo et al, 2003) have lead to the hypothesis that an angiogenic switch in DCIS may contribute to the transformation from in situ to invasive carcinoma. In DCIS, two distinct vascular patterns have been described: (1) a diffuse increase of MVD in the stroma and (2) an increase in the number of periductal microvessels, the latter presumably due to the direct release of angiogenic factors by neoplastic cells within the ducts (Guidi et al, 1994; Engels et al, 1997).

Angiogenesis as a multistep process is controlled by various positive and negative regulatory signals. Endogenous proangiogenic factors that could have an impact on regulation of angiogenesis in DCIS are, for example, VEGF, bFGF, ET-1, and their respective receptors; the sole exception to this is VEGFR-1 (Flt-1) which is supposed to mediate antiangiogenic effects. In the present study, we analysed expression of several angiogenic as well as lymphangiogenic growth factors and their receptors in a large series of DCIS to evaluate potential associations with established histopathological characteristics and to assess whether there are different expression patterns between the groups of DCIS with $(n=104)$ and without $(n=96)$ coexistent invasive carcinoma.

Vascular endothelial growth factor-A and its receptor KDR were expressed in the tumour cells of about half the cases, whereas Flt-1 expression was rarely observed (16\%). Expression of VEGF-A in tumour cells of DCIS has been reported previously and was demonstrated to correlate with the degree of angiogenesis (Guidi et al, 1997). However, to the best of our knowledge, the present publication is the first to describe expression of VEGF-A receptors, KDR and Flt-1, in DCIS. In general, KDR is recognised as the predominant signal transducer of tumour angiogenesis, whereas Flt-1 (and especially its soluble form) is a negative regulator of VEGF availability (Ferrara et al, 2003). In invasive breast cancer, expression of Flt-1 and KDR has been observed in 44 and $38 \%$ of cases, respectively (De Jong et al, 1998a). Our finding of a rare Flt1 expression as opposed to a considerably higher rate of KDR expression may therefore point to a presumably increased angiogenic activity in DCIS paralleled by the downregulation of antiangiogenic receptors while the so-called angiogenic switch.

In this study, VEGF-C and Flt-4, established mediators of angiogenesis (Cao et al, 1998; Valtola et al, 1999) and in particular of lymphangiogenesis (Jeltsch et al, 1997; Kinoshita et al, 2001), were expressed in the tumour cells of the majority of DCIS specimens ( 88 and $95 \%$, respectively). For invasive breast cancer, a similar rate of VEGF-C-positive cases has been reported previously (Nakamura et al, 2003). To date, there is only one other study published investigating VEGF-C expression in a small series of DCIS $(n=8)$. In that series, VEGF-C was secreted by the intraductal carcinoma cells and was suggested to act as a growth factor for Flt-4-positive periductal blood vessels and (less evidently) for lymphatic vessels (Valtola et al, 1999). This implicates an association of Flt-4 and its ligand VEGF-C with angiogenesis in DCIS. However, there are no published data on Flt4 expression in tumour cells of DCIS yet. Our findings on the presence of Flt-4 expression in the majority of intraductal tumour cells also suggest an autocrine growth-stimulatory pattern of VEGF-C via Flt-4 as described for cervical cancer (Van Trappen et al, 2003). However, a recently published study of Vleugel et al (2004) demonstrated that no intralesional increase in lymph vessel density occurs during breast carcinogenesis. Nonetheless, in general it is without doubt that the spread of tumour cells via the lymphatic system is one of the major causes of metastasis and consecutively tumour-related death. Therefore, the lymphangiogenic effects of intratumorously synthesised VEGF-C may be explained by a perilesional induction of stromal lymphangiogenesis.

In the present study, bFGF expression was rarely observed in DCIS (12\%), whereas almost all DCIS cases showed bFGF-R expression. To date, there are no further data available in the literature on expression of bFGF and its receptors in DCIS. Our observation on the small proportion of bFGF-expressing DCIS specimens strongly contrasts reports on a higher rate $(44 \%)$ of bFGF expression in invasive breast carcinomas (De Jong et al, 1998a). This may reflect an intermediate position of DCIS between normal breast tissue and invasive breast cancer, the latter reportedly showing increased bFGF levels as compared to nonmalignant tissue (Smith et al, 1999). Nonetheless, in DCIS, we observed an association between higher bFGF expression with favourable prognostic criteria (low grade, positive steroid hormone receptor status, and lack of Her-2/neu expression), as described earlier for invasive breast cancer (Smith et al, 1999). This is also in good agreement with survival data in patients with invasive breast carcinomas in which bFGF expression was found to correlate with a longer disease-free interval (Colomer et al, 1997). Thus, although it has been shown that bFGF expression is related to higher angiogenic activity (De Jong et al, 1998b), bFGF may represent an indicator for invasive breast carcinomas with favourable prognosis as well as for DCIS lesions less likely to progress to invasive breast cancer.

In our study, ET-1 was expressed in the tumour cells of $48 \%$. However, the ET receptors, $\mathrm{ET}_{\mathrm{A}} \mathrm{R}$ and $\mathrm{ET}_{\mathrm{B}} \mathrm{R}$, showed an unequal distribution: $\mathrm{ET}_{\mathrm{A}} \mathrm{R}$ was present in the majority $(76 \%)$ of DCIS whereas $\mathrm{ET}_{\mathrm{B}} \mathrm{R}$ expression was found significantly less frequently $(38 \%)$. We have previously shown that expression of the ET-axis is increased in invasive breast cancer and that, in particular, $\mathrm{ET}_{\mathrm{A}} \mathrm{R}$ expression correlates with more aggressive tumour types and poor survival (Wülfing et al, 2003a). Moreover, we found a significant positive correlation between expression of the ET-axis and vascularity as well as VEGF expression of breast carcinomas (Wülfing et al, 2004b). Thus, the ET-axis and especially $\mathrm{ET}_{\mathrm{A}} \mathrm{R}$ may represent a marker of malignant and angiogenic activity in breast cancer. In another study comparing expression of the ET-axis in a series $(n=88)$ of invasive breast carcinomas, concomitant DCIS, and normal breast tissue, we demonstrated a stepwise increase of ET-1 and $\mathrm{ET}_{\mathrm{A}} \mathrm{R}$ expression with disease progression, suggesting that expression of these proteins correlates with the acquisition of malignant potential and invasive behaviour (Wülfing et al, 2004a). The present study also highlights the potential role of $\mathrm{ET}_{\mathrm{A}} \mathrm{R}$ expression in breast carcinogenesis. These findings may have clinical relevance since $\mathrm{ET}_{\mathrm{A}} \mathrm{R}$ represents a potential target for antiangiogenic and antitumorigenic therapy (Nelson et al, 2003). It is therefore conceivable that the administration of selective $\mathrm{ET}_{\mathrm{A}} \mathrm{R}$ antagonists may prevent transformation from intraductal to invasive breast cancer.

Ductal carcinoma in situ is heterogeneous in its histology and clinical presentation, and so far there is no generally accepted 
model to predict progression to invasive carcinoma. Pure DCIS does not have the potential to metastasise and thereby leading to death. Therefore, the particular importance of DCIS is the risk of developing to invasive carcinoma.

In this study, comparative analysis of expression of these growth factors and their respective receptors in the groups of pure DCIS $v s$ coexistent DCIS revealed that expression of proangiogenic factors such as VEGF-C, KDR, Flt-4, and $\mathrm{ET}_{\mathrm{A}} \mathrm{R}$ was significantly more common in pure DCIS than in DCIS with an adjacent invasive carcinoma (coexistent DCIS). Conversely, Flt-1 as a negative regulator of VEGF availability and thus being regarded as an antiangiogenic receptor was expressed significantly more frequently in the group of coexistent breast carcinomas. These results indicate a higher angiogenic activity in DCIS without coexistent invasive carcinoma (pure DCIS). Several explanations are feasible for this rather unexpected finding: Our data, demonstrating quantitative differences between expression of angiogenic factors, suggest a biological difference among the groups of (a) pure DCIS and (b) DCIS with concomitant invasive carcinoma. This is consistent with findings from Teo et al (2002) describing a different vascular density and phenotype in pure DCIS vs DCIS associated with invasive carcinoma, the latter showing significantly greater numbers of $\mathrm{CD} 34+$ and $\mathrm{CD} 141+$ vessels and fewer staining for FVIII (Teo et al, 2002). Besides distinct vascular profiles in pure and coexistent DCIS, that study also showed a significant negative correlation between vascular density and the extent of necrosis of the tumour, and a correlation between vascular density and the nuclear grade was noted, being highest in the intermediate grade DCIS (Teo et al, 2002). The latter is also in agreement with our observation that the association of the proangiogenic growth factors and receptors with pure DCIS was considerably more pronounced in the subgroup of non-high-grade DCIS as compared with high-grade DCIS. This could indicate that the group of non-high-grade DCIS without coexistent invasive carcinoma is particularly angiogenic. Our results on different expression patterns of angiogenic factors in non-high-grade as opposed to high-grade DCIS is also compatible with the notion that distinct progression routes exist in the evolution from DCIS to invasive breast cancer (Buerger et al, 1999; Mommers et al, 2001). Also, the similarity in expression of $\mathrm{ET}_{\mathrm{A}} \mathrm{R}, \mathrm{VEGF}-\mathrm{C}$, Flt-4, and Her- 2/neu between the in situ and the concomitant invasive carcinomas and the observed close concordance with respect to nuclear grading between both components is in agreement with previous reports on different lines of genetic evolution of invasive breast cancer (Buerger et al, 1999, 2001; Mommers et al, 2001).

With respect to our findings, it is conceivable that determination of VEGF-C, $\mathrm{ET}_{\mathrm{A}} \mathrm{R}, \mathrm{KDR}$, and Flt-4 expression may facilitate discrimination of a more angiogenic subset within the group of non-high-grade DCIS without coexistent invasive carcinoma. Among non-high-grade DCIS, this more angiogenic group may have a higher probability of recurrence or of progression to invasiveness and thus presumably necessitates a risk-adapted therapy. This is of major clinical importance since approximately half of the local recurrences after treatment for a primary DCIS are invasive and no appropriate tumour marker is available yet that would allow for prediction of recurrence. Moreover, during the last years, antiangiogenic therapy for malignancies has been extensively investigated, and many novel agents representing several approaches to blocking tumour neovascularisation are in clinical trials (Eskens, 2004).

In conclusion, this study showed expression of VEGF-C and its receptor Flt-4, both representing lymphangiogenic growth factors, in intraductal tumour cells of nearly all DCIS lesions. Furthermore, most of the DCIS cases showed significant expression of various angiogenic growth factors. Our data therefore indicate that in situ carcinomas are capable of inducing angiogenesis and lymphangiogenesis. Moreover, we found a higher angiogenic activity in DCIS without coexistent invasive carcinoma (pure DCIS) as compared to DCIS with concomitant invasive carcinoma. This association of angiogenic factors with pure DCIS was considerably more pronounced in the subgroup of non-high-grade DCIS as compared with high-grade DCIS. One can therefore assume from these data that the group of non-high-grade DCIS without coexistent invasive carcinoma is particularly angiogenic. Determination of these angiogenic markers in pure DCIS may therefore facilitate discrimination of a more angiogenic subset with a potentially higher risk of progression. This subset of patients could benefit from a risk-oriented, targeted antiangiogenic therapy which represents a potential strategy for prevention of progression of DCIS to invasion.

\section{REFERENCES}

Bek EL, McMillen MA (2000) Endothelins are angiogenic. J Cardiovasc Pharmacol 36: S135-S139

Buerger H, Mommers EC, Littmann R, Simon R, Diallo R, Poremba C, Dockhorn-Dworniczak B, van Diest PJ, Boecker W (2001) Ductal invasive G2 and G3 carcinomas of the breast are the end stages of at least two different lines of genetic evolution. J Pathol 194: 165-170

Buerger H, Otterbach F, Simon R, Schafer KL, Poremba C, Diallo R, Brinkschmidt C, Dockhorn-Dworniczak B, Boecker W (1999) Different genetic pathways in the evolution of invasive breast cancer are associated with distinct morphological subtypes. J Pathol 189: 521-526

Cao Y, Linden P, Farnebo J, Cao R, Eriksson A, Kumar V, Qi JH, ClaessonWelsh L, Alitalo K (1998) Vascular endothelial growth factor induces angiogenesis in vivo. Proc Natl Acad Sci USA 95: 14389-14394

Colomer R, Aparicio J, Montero S, Guzman C, Larrodera L, Cortes-Funes H (1997) Low levels of basic fibroblast growth factor (bFGF) are associated with a poor prognosis in human breast carcinoma. Br J Cancer 76: 1215 1220

Dales JP, Garcia S, Carpentier S, Andrac L, Ramuz O, Lavaut MN, Allasia C, Bonnier P, Taranger-Charpin C (2004) Prediction of metastasis risk (11 year follow-up) using VEGF-R1, VEGF-R2, Tie-2/Tek and CD105 expression in breast cancer $(n=905)$. Br J Cancer 90: 1216-1221

De Jong JS, van Diest PJ, van der Valk P, Baak JPA (1998a) Expression of growth factors, growth inhibiting factors, and their receptors in invasive breast cancer. I: an inventory in search of autocrine and paracrine loops. J Pathol 184: $44-52$
De Jong JS, van Diest PJ, van der Valk P, Baak JPA (1998b) Expression of growth factors, growth inhibiting factors, and their receptors in invasive breast cancer. II: Correlations with proliferation and angiogenesis. J Pathol 184: 53-57

de Vries C, Escobedo JA, Ueno H, Houck K, Ferrara N, Williams LT (1992) The fms-like tyrosine kinase, a receptor for vascular endothelial growth factor. Science 255: 989-991

Engels K, Fox SB, Whitehouse RM, Gatter KC, Harris AL (1997) Distinct angiogenic patterns are associated with high-grade in situ ductal carcinomas of the breast. J Pathol 181: 207-212

Eskens FA (2004) Angiogenesis inhibitors in clinical development; where are we now and where are we going. Br J Cancer 90: 1-7

Ferrara N, Gerber HP, LeCouter J (2003) The biology of VEGF and its receptors. Nat Med 9: 669-676

Folkman J (1995) Angiogenesis in cancer, vascular, rheumatoid and other disease. Nat Med 1: 27-31

Folkman J, Watson K, Ingber D, Hanahan D (1989) Induction of angiogenesis during the transition from hyperplasia to neoplasia. Nature 339: $58-61$

Gasparini G (2001) Clinical significance of determination of surrogate markers of angiogenesis in breast cancer. Crit Rev Oncol Hematol 37: $97-114$

Gasparini G, Weidner N., Bevilacqua P, Maluta S, Palma PD, Caffo O, Barbareschi M, Boracchi P, Marubini E, Pozza F (1994) Tumour microvessel density, p53 expression, tumour size, and peritumoural 
lymphatic vessel invasion are relevant prognostic markers in nodenegative breast carcinoma. J Clin Oncol 12: 454-466

Guidi AJ, Fischer L, Harris JR, Schnitt SJ (1994) Microvessel density and distribution in ductal carcinoma in situ of the breast. J Natl Cancer Inst 86: $614-619$

Guidi AJ, Schnitt SJ, Fischer L, Tognazzi K, Harris JR, Dvorak HF, Brown LF (1997) Vascular permeability factor (vascular endothelial growth factor) expression and angiogenesis in patients with ductal carcinoma in situ of the breast. Cancer 80: $1945-1953$

Heimann R, Ferguson D, Powers C, Recant WM, Weichselbaum RR, Hellmann S (1996) Angiogenesis as a predictor of long-term survival for patients with node-negative breast cancer. J Natl Cancer Inst 88: 1764 1769

Holland R, Peterse JL, Millis RR, Eusebi V, Faverly D, van de Vijver MJ, Zafrani B (1994) Ductal carcinoma in situ: a proposal for a new classification. Semin Diagn Pathol 11: 167-180

Jeltsch M, Kaipainen A, Joukov V, Meng X, Lakso M, Rauvala H, Swartz M, Fukumura D, Jain RK, Alitalo K (1997) Hyperplasia of lymphatic vessels in VEGF-C transgenic mice. Science 276: 1423-1425

Kern FG, Lippman ME (1996) The role of angiogenic growth factors in breast cancer progression. Cancer Met Rev 15: 213 -219

Kinoshita J, Kitamura K, Kabashima A, Saeki H, Tanaka S, Sugimachi K (2001) Clinical significance of vascular endothelial growth factor-C (VEGF-C) in breast cancer. Breast Cancer Res Treat 66: 159-164

Kranz A, Mattfeldt T, Waltenberger J (1999) Molecular mediators of tumor angiogenesis: enhanced expression and activation of vascular endothelial growth factor receptor KDR in primary breast cancer. Int J Cancer 84: $293-298$

Luqmani YA, Graham M, Coombes RC (1992) Expression of basic fibroblast growth factor, FGFR1 and FGFR2 in normal and malignant human breast, and comparison with other normal tissues. Br J Cancer 66: $273-280$

Mason IJ (1994) The ins and outs of fibroblast growth factors. Cell 78: $547-552$

Millauer B, Wizigmann-Voos S, Schnurch H, Martinez R, Moller NP, Risau W, Ullrich A (1993) High affinity VEGF binding and developmental expression suggest Flk-1 as a major regulator of vasculogenesis and angiogenesis. Cell 72: 835-846

Mohammadi M, McMahon G, Sun L, Tang C, Hirth P, Yeh BK, Hubbard SR, Schlessinger J (1997) Structures of the tyrosine kinase domain of fibroblast growth factor receptor in complex with inhibitors. Science 276: 955-960

Mommers EC, Leonhart AM, Falix F, Michalides R, Meijer CJ, Baak JP, Diest PJ (2001) Similarity in expression of cell cycle proteins between in situ and invasive ductal breast lesions of same differentiation grade. J Pathol 194: 327 - 333

Mustonen T, Alitalo K (1995) Endothelial receptor tyrosine kinases involved in angiogenesis. J Cell Biol 129: 895-898

Nakamura Y, Yasuoka H, Tsujimoto M, Yang Q, Tsukiyama A, Imabun S, Nakahara M, Nakao K, Nakamura M, Mori I, Kakudo K (2003) Clinicopathological significance of vascular endothelial growth factor-C in breast carcinoma with long-term follow-up. Mod Pathol 16: 309-314

Nelson J, Bagnato A, Battistini B, Nisen P (2003) The endothelin axis: emerging role in cancer. Nat Rev Cancer 3: $110-116$

Obermaier A, Kucera E, Mayerhofer K, Speiser P, Seifert M, Czerwnka K, Kaider A, Leodolter S, Kainz C, Zeillinger R (1997) Vascular endothelial growth factor (VEGF) in human breast cancer: correlation with diseasefree survival. Int $J$ Cancer 74: $455-458$

Pajusola K, Aprelikova O, Pelicci G, Weich H, Claesson-Welsh L, Alitalo K (1994) Signalling properties of FLT4, a proteolytically processed receptor tyrosine kinase related to two VEGF receptors. Oncogene 9: 3545-3555

Salani D, Di Castro V, Nicotra MR, Rosano L, Tecce R, Venuti A, Natali PG, Bagnato A (2000) Role of endothelin-1 in neovascularization of ovarian carcinoma. Am J Pathol 157: 1537-1547

Smith K, Fox SB, Whitehouse R, Taylor M, Greenall M, Clarke J, Harris AL (1999) Upregulation of basic fibroblast growth factor in breast carcinoma and its relationship to vascular density, oestrogen receptor, epidermal growth factor receptor and survival. Ann Oncol 10: 707-713

Spinella F, Rosano L, Di Castro V, Natali PG, Bagnato A (2002) Endothelin1 induces vascular endothelial growth factor by increasing hypoxiainducible factor $1 \alpha$ in ovarian cancer cells. J Biol Chem 277: 27850 - 27855

Teo NB, Shoker BS, Jarvis C, Martin L, Sloanel JP, Holcombe C (2002) Vascular density and phenotype around ductal carcinoma in situ (DCIS) of the breast. Br J Cancer 86: 905-911

Teo NB, Shoker BS, Jarvis C, Martin L, Sloane JP, Holcombe C (2003) Angiogenesis and invasive recurrence in ductal carcinoma in situ of the breast. Eur I Cancer 39: 38-44

Valtola R, Salven P, Heikkila P, Taipale J, Joensuu H, Rehn M, Pihlajaniemi T, Weich H, deWaal R, Alitalo K (1999) VEGFR-3 and its ligand VEGF-C are associated with angiogenesis in breast cancer. Am J Pathol 154: $1381-1390$

Van Trappen PO, Steele D, Lowe DG, Baithun S, Beasley N, Thiele W, Weich H, Krishnan J, Shepherd JH, Pepper MS, Jackson DG, Sleeman JP, Jacobs IJ (2003) Expression of vascular endothelial growth factor (VEGF)-C and VEGF-D, and their receptor VEGFR-3, during different stages of cervical carcinogenesis. J Pathol 201: 544-554

Vleugel MM, Bos R, van der Groep P, Greijer AE, Shvarts A, Stel HV, van der Wall E, van Diest PJ (2004) Lack of lymphangiogenesis during breast carcinogenesis. Clin Pathol 57: 746-751

Wülfing P, Diallo R, Kersting C, Wülfing C, Poremba C, Greb RR, Bocker W, Kiesel L (2004a) Endothelin-1, Endothelin-A- and Endothelin-Breceptor expression in preinvasive and invasive breast disease. Oncol Rep 11: $791-796$

Wülfing P, Diallo R, Kersting C, Wülfing C, Poremba C, Rody A, Greb RR, Böcker W, Kiesel L (2003a) Expression of Endothelin-1, Endothelin-A and Endothelin-B receptor in human breast cancer and correlation with long-term follow-up. Clin Cancer Res 9: 4125-4131

Wülfing P, Diallo R, Müller C, Wülfing C, Poremba C, Heinecke A, Rody A, Greb RR, Böcker W, Kiesel L (2003b) Analysis of cyclooxygenase-2 expression in human breast cancer: high throughput tissue microarray analysis. J Cancer Res Clin Oncol 129: 375-382

Wülfing P, Kersting C, Tio J, Fischer RJ, Wülfing C, Poremba C, Diallo R, Böcker W, Kiesel L (2004b) Endothelin-1, Endothelin-A- and EndothelinB-receptor expression is correlated with VEGF expression and angiogenesis in breast cancer. Clin Cancer Res 10: 2393-2400

Yoshiji H, Gomez DE, Shibuya M, Thorgeirsson UP (1996) Expresion of vascular endothelial growth factor, its receptor and other angiogenic factors in human breast cancer. Cancer Res 56: 2013-2016

Zhukova LG, Zhukov NV, Lichinitser MR (2003) Expression of Flt-1 and Flk-1 receptors for vascular endothelial growth factor on tumor cells as a new prognostic criterion for locally advanced breast cancer. Bull Exp Bio Med 135: 478-481 